\title{
The effect of tinted spectacle lenses on contrast sensitivity and colour vision
}

\author{
M Shaik, PD Majola, LM Nkgare, NB Nene, C Singh, R Hansraja and N Rampersad ${ }^{\mathrm{b}}$
}

Discipline of Optometry, Faculty of Health Sciences, University of KwaZulu Natal, Private Bag X54001, Durban, 4000 South Africa

${ }^{a}<$ hansrajr@ukzn.ac.za $>$ and ${ }^{\mathrm{b}}<$ rampersadn@ukzn.ac.za $>$

Received 21 October 2012; revised version accepted 17 June 2013

\begin{abstract}
Aim: Spectacle wearers often prefer tinted lenses to clear or non-tinted lenses for their protection against harmful radiation, improved cosmesis, enhancement of visual performance and effects on colour vision. Among the available tinted lenses on the market blue, brown and grey tinted spectacle lenses are popular with varying grades ranging from $\mathrm{A}$ to $\mathrm{D}$. Due to reduced transmission of light through such lenses, the optical system of the eyes and the environmental vision may be temporarily altered. Colour vision (CV) and contrast sensitivity (CS) are important aspects of this altered visual world. This study investigated the effect of spectacle lenses of varying grades of tint on $\mathrm{CS}$ and $\mathrm{CV}$.
\end{abstract}

Method: The study adopted a pre- and posttest research design and a sample of 90 participants were selected from the University of KwaZuluNatal student population using convenience sampling. Each participant was screened for pathology, dyschromatopsia, severe dry eyes (TBUT $<5$ seconds), and the presence of any more than low ametropia. Thereafter each successful participant was tested for CS and CV with their habitual prescription and then tested randomly with a white (clear) lens (placebo) and tinted (blue, brown, and grey) spectacle lenses made of CR39 mate- rial each having grades $\mathrm{A}, \mathrm{B}$ and $\mathrm{C}$ over their habitual state. Light transmission was $85 \%, 75 \%$, and $50 \%$ for grades $\mathrm{A}, \mathrm{B}$, and $\mathrm{C}$ respectively. The Functional Acuity Contrast Test (FACT) chart and American Optical Hardy, Rand, and Rittler (AO HRR) were used for the assessment of CS and CV respectively.

Results: The data was analysed using the Statistical Package of Social Science (SPSS) version 18. Compared to the habitual state, contrast sensitivity was enhanced with all the tinted lenses. The greater enhancement was for low spatial frequencies (LSF) and least for high spatial frequencies (HSF). With all tints Grade $\mathrm{C}$ had the least enhancement for very HSF. Many subjects showed no change in CV with any of the lenses used. The grey tint showed greater enhancement of $\mathrm{CV}$ as the density increases. Blue and brown tints showed a similar trend with grade B enhancing $\mathrm{CV}$ the most while grade $\mathrm{C}$ resulted in the least reduction of $\mathrm{CV}$.

Conclusion: Grade A, B, and C of blue, brown and grey tinted spectacle lenses do not alter colour vision significantly but for the selected levels of transmission of the tints used, contrast sensitivity can be improved to some extent.

Key words: Contrast sensitivity, colour vision, FACT chart, AO Hardy Rand Rittler colour test, spatial frequency, tinted spectacle lenses 


\section{Introduction}

Vision is an asset to all (creation) and even though visual impairment is not necessarily life threatening, it can be disabling in certain daily activities. Visual impairment due to refractive error is often compensated for by a variety of ophthalmic devices but most often with spectacle lenses. Thus, it is of utmost importance to be well aware of how any ophthalmic device may influence visual performance. Tinted spectacle lenses are the most common type of ophthalmic device aside from clear spectacle lenses. The purpose of tinted spectacle lenses is to reduce the transmission of light ${ }^{1}$. However, it is essential that such lenses do not hinder a person's visual performance.

Spectacle lens tints are prescribed by optometrists for many reasons. According to Ramkissoon et $a l^{2}$ the purpose of tints are mainly to provide protection from exposure to high levels of ultraviolet radiation (UV) and infrared radiation (IR), improve colour perception in colour deficient individuals, decrease glare from reflective surfaces such as snow, sand, and water, decrease illumination and thereby decrease sensitivity to light, decrease light scatter in conditions such as cataract, albinism and retinitis pigmentosa and improve cosmesis in disfigurements such as strabismus and decrease asthenopia. Tints are also used in patients with severe dry eyes (tear break up time (TBUT) $<5$ seconds) ${ }^{3}$.

Tinting a spectacle lens reduces transmission of light passing through the lens and striking the retina ${ }^{1}$. The percentage of incident light that is transmitted through the lens is called transmittance ${ }^{4}$. For a tinted lens, the wavelength of light which the lens reduces transmittance is actually the opponent colour of that tinted lens ${ }^{1}$. For example, a strong yellow tint reduces the transmittance of blue light (its opponent colour). Thus all the different colours (or wavelengths of light) would have different transmittance values. The density of the tint can be varied as well to produce different grades of the tint, which in turn have their separate transmittance values. Furthermore, different lenses from different companies have different transmittance values for their lenses, which can be measured by using a spectrophotometer ${ }^{5}$.

In South Africa and areas with warmer climates elsewhere, tinted lenses are of utmost importance. Due to the climate and harmful UV and IR exposure, many people in South Africa are at a high risk for ocular complications such as pingueculae, pterygia, dry eyes, cataracts, et ceter $a^{3,6}$. This results in people using tinted lenses for proper eye care protection. But, due to the socio-economic status of many South Africans, they may not be able to afford photochromic or transition lenses and thus may rely on more conventional (fixed) tints.

Currently there is an increase in usage of tinted lenses in the form of sunglasses and tinted spectacle lenses ${ }^{7}$. Besides traditional grey, green, and brown tinted lenses other colours such as blue, violet and yellow are used ${ }^{7}$. In this study, only the more commonly used tints (blue, brown and grey) were evaluated. With an increase in the use of tinted lenses, variables of visual performance like contrast sensitivity, colour vision and visual acuity should preferably not be affected negatively ${ }^{7}$. The two components of visual performance evaluated in this research study were contrast sensitivity and colour vision.

Contrast sensitivity can be defined as "the degree of blackness to whiteness of a target or the luminance level of an object when compared with the luminance of its surrounding background"s. The normal eye is maximally sensitive to $2-5$ cycles per degree (cpd) of spatial frequency and less sensitive to frequencies in the extremities ${ }^{8}$. The high frequencies cut-off/extremity is associated with the packing density of the retinal photoreceptors cells therefore a finer matrix can resolve a finer grating, while the low frequency cut-off is due to lateral inhibition within the retinal ganglion cells ${ }^{9}$. Contrast sensitivity can be impaired without there being any abnormal results in traditional acuity tests, that is measured using the Snellen chart $^{8}$. Thus, testing contrast sensitivity is an important tool for measuring functional visual changes as it assesses the quality of a patient's available vision ${ }^{8}$. It is also important to note that contrast sensitivity varies between individuals and also gradually declines with age ${ }^{6}$. Furthermore, other ocular abnormalities such as cataracts and glaucoma may also influence contrast sensitivity ${ }^{6}$.

Colour vision is another important aspect of visual performance. Colour vision is the "sense of sight which provides an appreciation of the difference in the physical composition of wavelengths of light that excite the retina" 10 . Colour vision is also different for every individual as it involves the complicated pro- 
cess of perception. Colour perception in humans is due to the presence of three different cone photoreceptors (that are sensitive to long, medium, and short wavelengths of light), all of which are functioning in the trichromatic human retina. Any deficiency or malfunctioning of these photopigments will affect a person's colour perception.

Many occupations such as flying an aircraft, captaining a ship or some areas of engineering require normal colour vision. Good colour vision is also important in driving, to properly see road signs and traffic signals ${ }^{11}$. Sportsmen also require adequate colour vision and Williams et $a l^{12}$ have shown that tinted lenses improve a dyslexic child's reading performance and ocular comfort. Many of these children were found to have certain vision anomalies such as accommodative, binocular and ocular motor dysfunctions and tinted lenses may improve children's reading ability and perception, increase periods of sustained reading time and reduce or remove visual symptoms such as headaches, eyestrain, blurring of print, light sensitivity and watery eyes.

A study done by de Fez et $a l^{7}$ compared the performance in contrast detection and colour discrimination tasks of a set of tinted lenses (blue, green, brown and yellow) with that of grey filters of equal luminance. The results showed that yellow lenses slightly enhanced the contrast of a scene. Dain $e t a l^{11}$ showed the effect of different sunglass tints on traffic signal detection and recognition for colour normal and colour deficient observers. They found that many sunglass tints permitted for drivers and riders cause a more measurable decrease in detecting and recognising traffic signals for colour deficient observers as opposed to colour normals. Diego et al ${ }^{13}$ studied the influence of luminance level on visual performance with disposable soft cosmetic tinted contact lenses (blue, blue topaz, green, green amazon, grey, hazel, and violet) by Bausch \& Lomb (Optima Colors $\left.{ }^{\circledR}\right)$. Their results showed abnormal contrast sensitivity function and higher error scores in colour vision testing at lower luminance levels. However, there was no statistically significant difference in participants' visual performances between wearing the coloured or clear contact lenses. The change in luminance was important, as with a decrease in luminance levels, the pupil size enlargened to a size greater than the clear centre of the tinted contact lens.
The purpose of this study therefore was to investigate the effect of tinted spectacle lenses and their grades on contrast sensitivity and colour vision. The findings of this study could be used to raise awareness among optometrists of which tints might have the best outcome on visual performance.

Patients might choose tinted lenses for cosmetic reasons but may not necessarily be aware of the effect of these tints on visual performance. Thus, another important rationale for this study is to inform optometrists of the possible influence tints could have on the daily activities or occupations of their patients and thereby guide them in choosing the tint with the least adverse effects and also make them aware of any possible changes to the perception of their environment.

\section{Methods}

\section{Study design and sample}

A pre- and post-test study design was used. Ethical clearance was obtained from the Faculty of Health Sciences at the University of Kwazulu Natal prior to commencement of the study (FECHSC 019/11). Once ethical clearance was obtained a pilot study was conducted to refine the study procedure. Informed consent was obtained from all participants prior to data collection. Thereafter a questionnaire was administered and visual acuity (VA), ophthalmoscopy, TBUT and the American Optical Hardy Rand Rittler colour vision test were used in screening participants to ensure that they met the inclusion criteria. In the case of ametropes, refractive error for each participant was compensated for with trial lenses before either contrast sensitivity or colour vision testing was performed. Refractive compensation was determined according to the participant's spectacle prescription. All tests were performed monocularly including the screening tests. Both the lenses and tests (contrast sensitivity and colour vision) were presented randomly to the participants. This method was adopted to ensure randomisation of clinical tests and presentation of the lenses to minimize any learning or fatigue effects. For each test, instructions, recording, and interpretations was standardised amongst the researchers. A single researcher captured results for contrast sensitivity while another conducted the test on each participant. The same applied for colour vision testing. No calibration was required for either 
the screening or main tests. All tests were conducted in the same environment for each participant.

The study population comprised of all students at the University of KwaZulu Natal-Westville campus who were registered for the academic year 2011. Convenience sampling was employed to select ninety participants. Participants were chosen using the criteria outlined in Table 1.

Table 1: Inclusion and exclusion criteria

\begin{tabular}{|l|l|}
\hline INCLUSION & EXCLUSION \\
\hline $\begin{array}{l}\text { Emmetropes and low am- } \\
\text { etropes }(0.25 \text { to }-3.00 \mathrm{D})\end{array}$ & Ocular pathology \\
\hline $\begin{array}{l}\text { Compensated VA of } 6 / 6 \text { or } \\
\text { better }\end{array}$ & Colour vision defects \\
\hline Trichromats & $\begin{array}{l}\text { Ocular or systemic medica- } \\
\text { tions }\end{array}$ \\
\hline Age $18-30$ years & Systemic diseases \\
\hline Either gender & Contact lens wearers \\
\hline All races & $\begin{array}{l}\text { Severe dry eye }(\text { Schirmer's } \\
<10 \mathrm{~mm}, \text { TBUT }<5 \mathrm{sec})^{3}\end{array}$ \\
\hline
\end{tabular}

All tests were conducted on one eye only including the screening tests. Emmetropes as well as those classified as low ametropes (myopia or hyperopia), were included in the study. Ametropes were compensated for, using the participant's spectacle prescription determined from a vertometer. The Snellen chart, American Optical Hardy Rand Rittler test, an ophthalmoscope and a slit lamp were the instruments used in testing VA, colour vision, ocular pathology and TBUT respectively.

\section{Study procedure}

The three main data gathering instruments used in this study were the Functional Acuity Contrast Test (FACT) chart for contrast sensitivity testing, the American Optical Hardy Rand Rittler (AO HRR) test for colour vision testing and a set of three tinted lenses of three different grades each together with a clear lens.

The lenses used were made of CR39. The tints used were grey, blue and brown with grades A, B and $\mathrm{C}$ of each colour as well as a white (clear) lens, resulting in ten lenses in total. Light transmission for the grades $\mathrm{A}, \mathrm{B}$, and $\mathrm{C}$ were $85 \%, 75 \%$, and $50 \%$ respectively. All the lenses were plano, flat form with the same thickness. The lenses were cut and fitted into lens holders for ease of use with a trial frame.

Contrast sensitivity was tested using the Functional Acuity Contrast Test (FACT) chart. Participants were tested monocularly, under standard room illuminaton, with the chart placed $3 \mathrm{~m}$ away from the participant and $1 \mathrm{~m}$ above the ground. The FACT chart has been established by previous studies as a suitable test to measure contrast sensitivity function ${ }^{14-16}$. A study by Pesudovs et $a l^{15}$ to investigate the repeatability and sensitivity of the FACT revealed that test-retest intra-class correlation coefficients varied from 0.18 to 0.45 . Bland-Altman limits of agreement across spatial frequencies were between \pm 0.30 to $\pm 0.75 \log \mathrm{CS}$ for $\mathrm{FACT}^{15}$. These values indicate poor repeatability of the FACT chart, however, that study was done on post-LASIK and pre-cataract subjects in whom the optical system may be altered. No other study was found that investigated the repeatability of the FACT chart on normal subjects. When performing the test, the last correct response for each row was recorded on the recording sheet, where the contrast sensitivity function curve was plotted. The contrast sensitivity values obtained were used to interpret the findings.

Colour vision was tested using the AO HRR pseudoisochromatic plate test. This test was conducted monocularly under normal room illumination $(\approx 300$ lux) with the booklet $75 \mathrm{~cm}$ away from the participant ${ }^{17}$. The correct responses were marked with a tick on the recording sheet. On the first time the test was done, plates 1-4 were used to demonstrate how the test works. Plates 5-10 were used for screening and plates 11-24 were used for diagnosis. According to the National Research Council ${ }^{18}$ in 1981 many authors have compared the AO HRR test to other plates and lanterns and it has been found that this test detects at least 85 to $90 \%$ of colour-defective observers who were classified by the Nagel Anomaloscope, which is regarded as the gold standard for colour vision assessment.

The entire testing procedure including the screening tests took an average of 45 minutes per participant. Two participants were examined simultaneously, one starting at contrast sensitivity and the other at colour vision. Five lenses were presented to the participant at contrast sensitivity and results recorded. The participant then moved to colour vision, being tested with the other five lenses and returned to contrast sensitivity to be examined with the remaining five lenses. 
Testing concluded with the assessment of colour vision with the remaining five lenses. The same procedure was performed for the participant starting at colour vision.

Data was captured and analysed using the Statistical Package for Social Sciences (SPSS, version 18.0) with the guidance of the faculty statistician. The data collected was described in terms of frequencies and means, and the Wilcoxon Signed Ranks test was used to investigate correlations. Statistical significance was set at the $95 \%$ confidence level.

\section{Results}

\section{Contrast sensitivity}

Figure 1 shows the effect that each study lens had on contrast sensitivity when compared to the habitual situation shown in red. The mean values $(N=90$ participants) of contrast sensitivity were used to plot the various curves on the graph. The habitual curve (red curve) is an average for the 90 participants wearing their habitual compensations (with BCVA of 6/6) although some were emmetropes.

For most spatial frequencies $(<\approx 9 \mathrm{cpd})$, but es- pecially the lower frequencies, all the tinted lenses enhanced the participants' contrast sensitivity when compared to their habitual conditions. When compared to the habitual state, the degree of improvement was the greatest at low spatial frequencies, followed by the middle spatial frequency and the least enhancement was at the higher spatial frequencies.

The Wilcoxon Signed Ranks test revealed that when compared to the habitual situation, for all the lenses at 1.5 and $3 \mathrm{cpd}$ there was a statistically significant improvement at the $95 \%$ confidence interval (Table 2). There was also no significant difference between habitual conditions and all $\mathrm{C}$ tints and the blue $\mathrm{B}$ at $6 \mathrm{cpd}$. While at 12 and $18 \mathrm{cpd}$, against the habitual situation there was a statistically significant improvement for the white lens and blue A, whereas grey $\mathrm{C}$ showed a statistically significant reduction at $12 \mathrm{cpd}$. The Wilcoxon Signed Ranks test was used as opposed to the dependant $t$-test as this research did not assume normality in the data, hence the $t$-test proved to be inappropriate ${ }^{19}$.

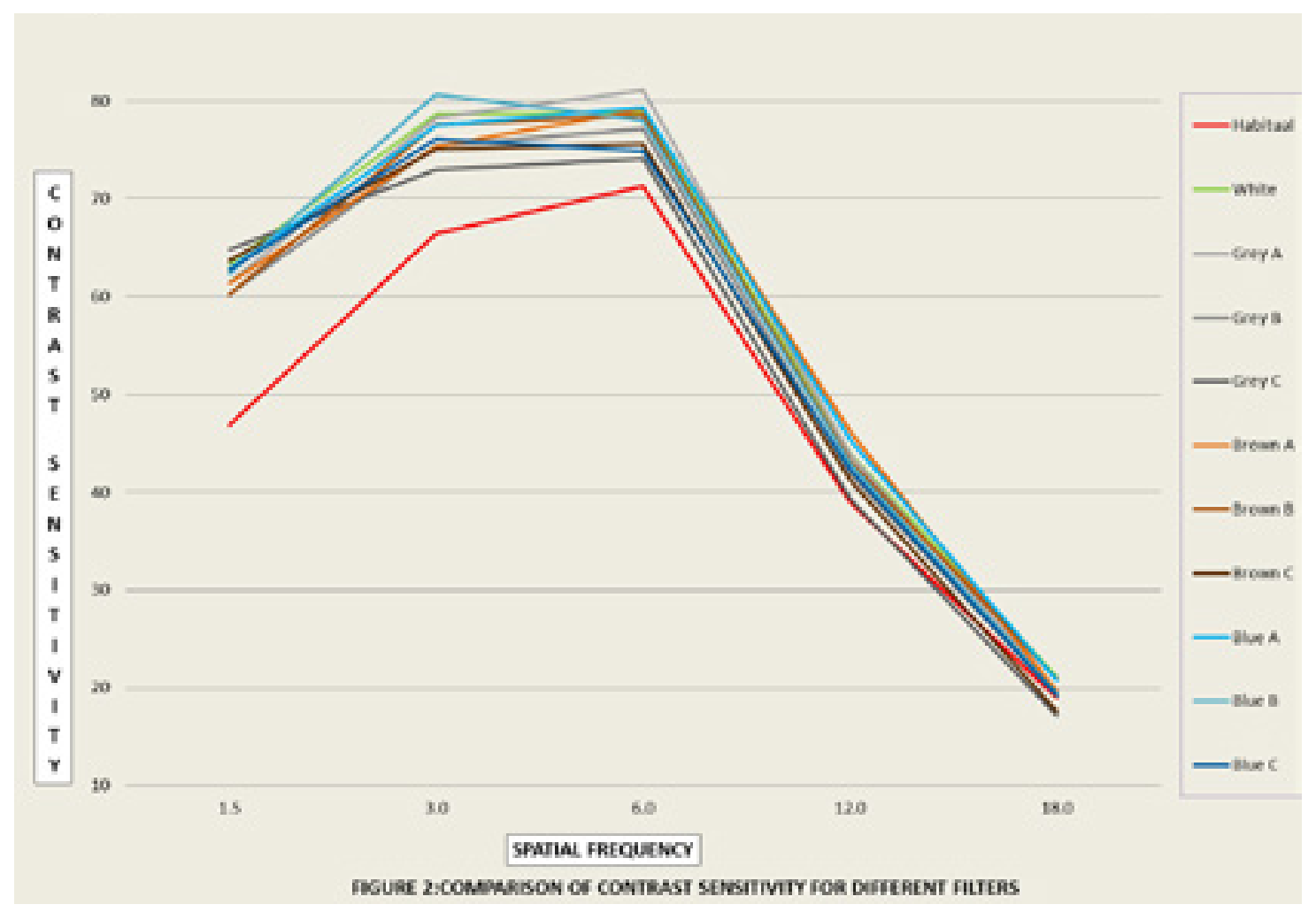

Figure 1: Comparison of the mean values of contrast sensitivity between different filters and their grades at varying spatial frequencies to the habitual situations Figures 2, 3 and 4 demonstrate how varying densities 
Table 2: Mean contrast sensitivity scores for various spatial frequencies and the significance values when compared to habitual conditions

\begin{tabular}{|c|c|c|c|c|c|c|c|c|c|c|c|}
\hline \multirow{2}{*}{ FILTERS } & \multirow{2}{*}{$\mathrm{N}$} & \multicolumn{2}{|c|}{$1.5 \mathrm{cpd}$} & \multicolumn{2}{|c|}{$3 \mathrm{cpd}$} & \multicolumn{2}{c|}{$6 \mathrm{cpd}$} & \multicolumn{2}{c|}{$12 \mathrm{cpd}$} & \multicolumn{2}{c|}{$18 \mathrm{cpd}$} \\
\cline { 3 - 13 } & & Mean & Sign. & Mean & Sign. & Mean & Sign. & Mean & Sign. & Mean & Sign. \\
\hline Habitual & 90 & 46.89 & & 66.44 & & 71.26 & & 38.96 & & 18.98 & \\
\hline White & 90 & $\mathbf{6 3 . 3 3}$ & 0.00 & $\mathbf{7 8 . 6 1}$ & 0.00 & $\mathbf{7 8 . 8 1}$ & 0.02 & $\mathbf{4 4 . 0 4}$ & 0.00 & $\mathbf{2 1 . 1 3}$ & 0.02 \\
\hline Grey A & 90 & $\mathbf{6 1 . 4 6}$ & 0.00 & $\mathbf{7 8 . 2 9}$ & 0.00 & $\mathbf{8 1 . 1 2}$ & 0.00 & $\mathbf{4 3 . 9 1}$ & 0.01 & 19.70 & 0.36 \\
\hline Grey B & 90 & $\mathbf{6 0 . 2 2}$ & 0.00 & $\mathbf{7 5 . 3 8}$ & 0.00 & $\mathbf{7 7 . 1 7}$ & 0.04 & 41.90 & 0.24 & 19.14 & 0.92 \\
\hline Grey C & 90 & $\mathbf{6 4 . 8 4}$ & 0.00 & $\mathbf{7 2 . 9 8}$ & 0.02 & 74.14 & 0.47 & 39.33 & 0.86 & $\mathbf{1 7 . 1 9}$ & 0.02 \\
\hline Brown A & 90 & $\mathbf{6 1 . 3 4}$ & 0.00 & $\mathbf{7 5 . 3 2}$ & 0.00 & $\mathbf{7 9 . 1 3}$ & 0.02 & $\mathbf{4 6 . 2 7}$ & 0.00 & 19.63 & 0.36 \\
\hline Brown B & 90 & $\mathbf{6 0 . 2 0}$ & 0.00 & $\mathbf{7 7 . 6 1}$ & 0.00 & $\mathbf{7 8 . 5 0}$ & 0.01 & 43.24 & 0.06 & 20.87 & 0.05 \\
\hline Brown C & 90 & $\mathbf{6 3 . 6 4}$ & 0.00 & $\mathbf{7 5 . 0 4}$ & 0.00 & 75.56 & 0.32 & 41.20 & 0.23 & 17.61 & 0.10 \\
\hline Blue A & 90 & $\mathbf{6 2 . 8 1}$ & 0.00 & $\mathbf{7 7 . 5 2}$ & 0.00 & $\mathbf{7 9 . 2 6}$ & 0.01 & $\mathbf{4 5 . 4 1}$ & 0.00 & $\mathbf{2 0 . 7 9}$ & 0.04 \\
\hline Blue B & 90 & $\mathbf{6 2 . 3 3}$ & 0.00 & $\mathbf{8 0 . 7 0}$ & 0.00 & 77.97 & 0.11 & $\mathbf{4 2 . 9 3}$ & 0.03 & 19.43 & 0.42 \\
\hline Blue C & 90 & $\mathbf{6 2 . 7 6}$ & 0.00 & $\mathbf{7 6 . 0 7}$ & 0.00 & 74.91 & 0.27 & 42.34 & 0.09 & 19.27 & 0.72 \\
\hline
\end{tabular}

for the same colour tint affect contrast sensitivity.

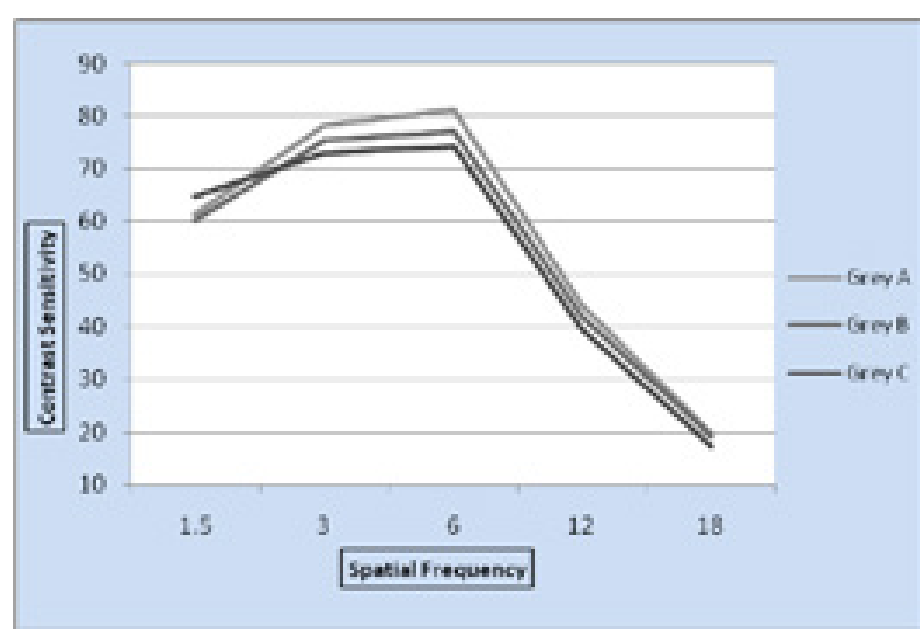

Figure 2: Contrast sensitivity functions for the varying densities (A, B and C) of the grey tint

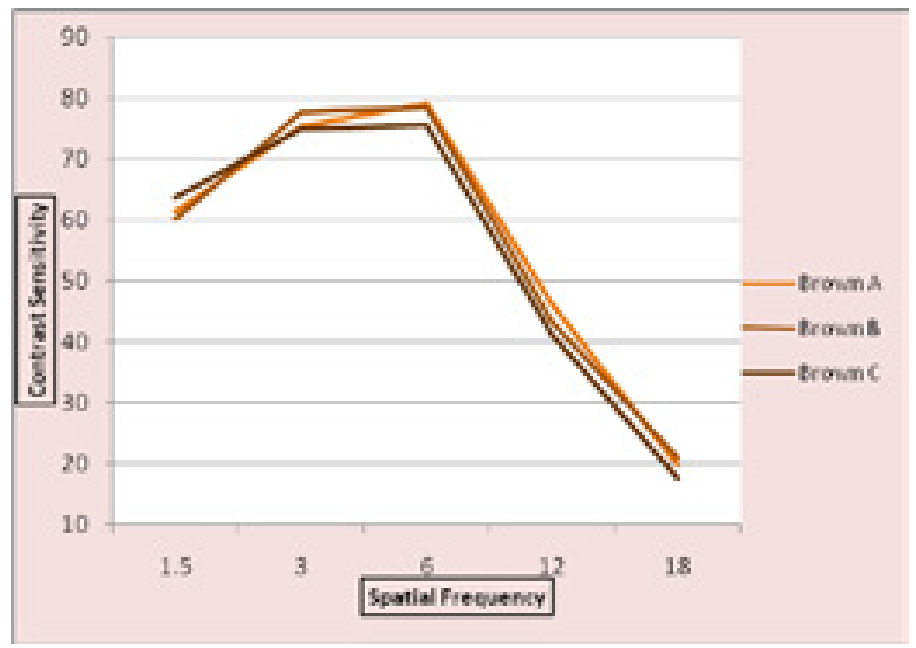

Figure 3: Contrast sensitivity functions for the varying densities (A, B and C) of the brown tint

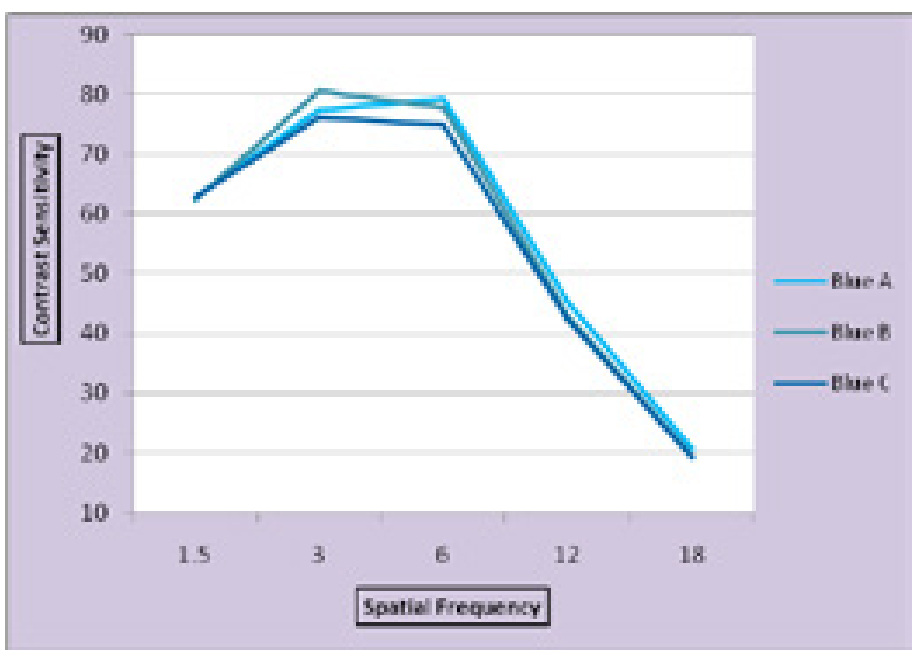

Figure 4: Contrast sensitivity functions of the varying densities (A, B and C) of the blue tint

The A tints revealed the highest contrast sensitivity function at 6, 12 and $18 \mathrm{cpd}$. Grade B produced the lowest contrast sensitivity function at $1.5 \mathrm{cpd}$. However, contrast sensitivity function was the highest at $3 \mathrm{cpd}$ with this grade for the brown and blue tints only. Grade $\mathrm{C}$ tints appeared to have the highest contrast sensitivity function for $1.5 \mathrm{cpd}$, however, contrast sensitivity reduced as spatial frequency increased.

In comparing how the three colours of tint for a specific density may affect contrast sensitivity, results showed that statistically significant difference were only found among all the colours in comparison to each other for the highest density (Grade C) at $18 \mathrm{cpd}$. 


\section{Colour vision}

The results depicted in Figure 5 shows the effect of the tints grey, brown, blue and the white lens on colour perception. All responses were compared to the participants' habitual lens prescriptions, which served as the control. The data was collected and categorised as either being the same, which meant that there was no change from the habitual, enhanced, that is, the participant could identify more plates correctly or reduced where Sthe participant identified less plates correctly. The majority of the participants (more than $70 \%$ of the sample) experienced no change in colour perception with all tints including the white lens. In $21.1 \%$ of the sample, the greatest enhancement achieved was with the grey tint followed by the blue tint $(20 \%)$, brown (15.9\%) and white $(12.2 \%)$.

The greatest reduction in the colour vision test was observed with the white lens $(8.9 \%)$, followed by blue (7\%), brown (6.7\%) and grey (5.2\%). When comparing the different colours of the tinted spectacle lenses, blue tints were found to distort results in the colour vision test the most.

The effect of the varying grades of tints on colour perception was also assessed, as is illustrated in Figure 6. When comparing the grades of tints to the habitual situation, the highest enhancement was found with blue B $(26.7 \%)$ while the greatest reductions was with the white lens, brown B and blue A tints (8.9\%). The grey tints showed a pattern whereby as the density increased from grade $\mathrm{A}$ to $\mathrm{C}$, there was a greater enhancement in participants' colour perception $(18.9 \%, 21.1 \%$ and $23.3 \%$ respectively). Brown and blue tints showed a similar trend with the varying grades, where the greatest enhancement was by grade

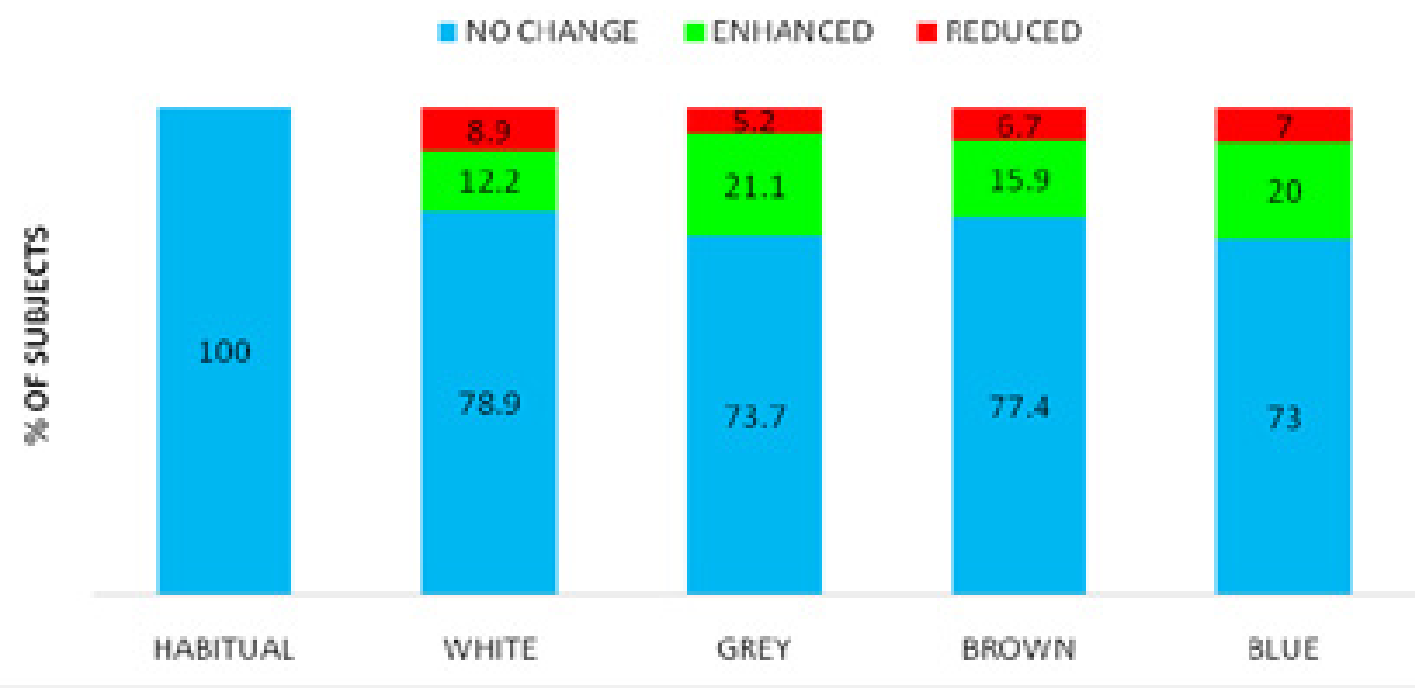

Figure 5: The effect of tinted spectacle lenses on results from the colour vision test that was applied

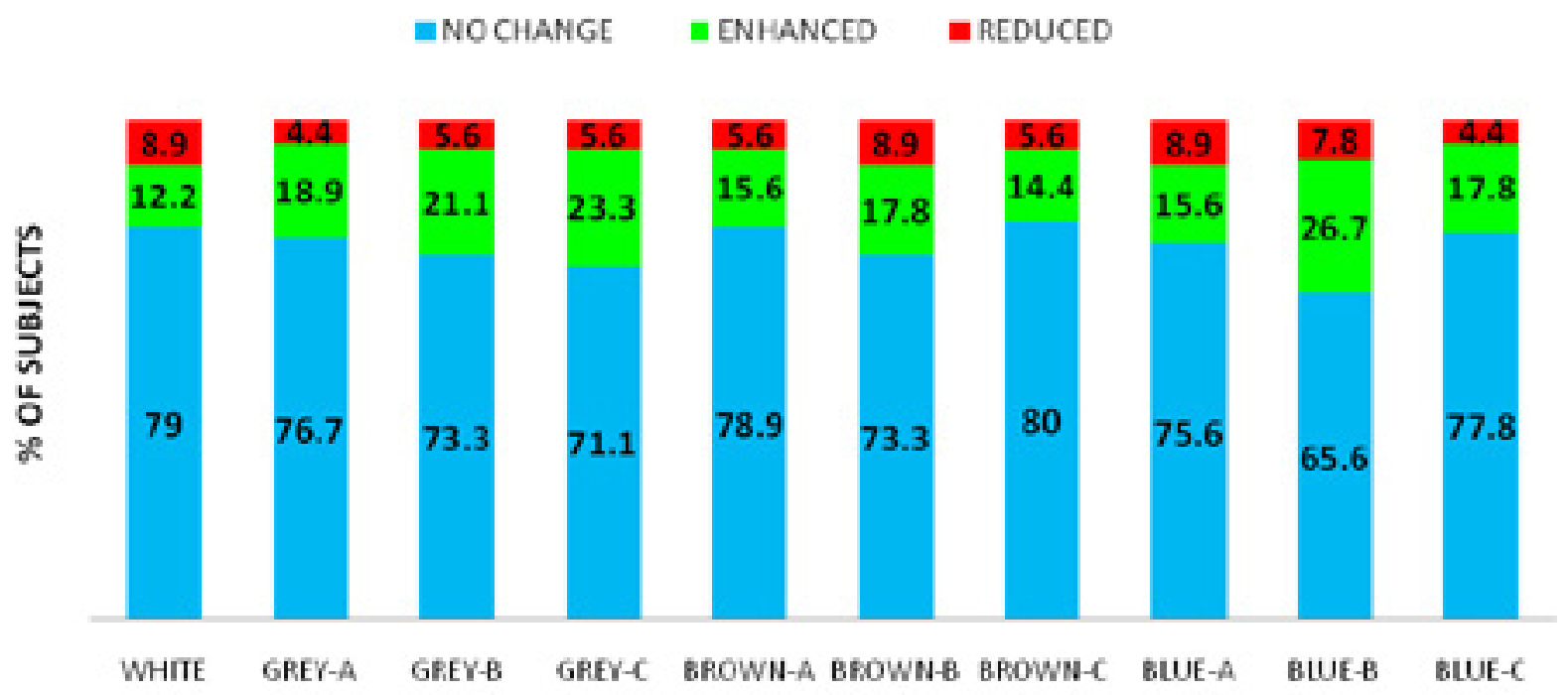

Figure 6: Effect of the varying grades of tinted spectacle lenses on colour vision 
$\mathrm{B}$ and the least reduction was by grade $\mathrm{C}$.

\section{Discussion}

\section{Contrast sensitivity}

A critical advantage of tinted lenses is their ability to decrease glare from reflective surfaces. In decreasing glare, objects on a surface become more clearly noticeable, thus improving contrast. This was found to be the case with the study lenses at spatial frequencies of 1.5, 3 and $6 \mathrm{cpd}$. Similar findings were reported by Lee et $a l^{20}$ who attributed the increase in contrast sensitivity threshold at low to middle spatial frequencies to the tints decreasing glare. Outdoor occupations as well as piloting and sports require optimum contrast sensitivity function at low to middle spatial frequencies. Hence, tints may be considered in these occupations or sports.

At high spatial frequencies, however, the contrast sensitivity function decreases due to the optical imperfections of the human eye and the size of individual foveal cones ${ }^{21}$. This explains the minimal improvement on average that the study lenses had at spatial frequencies 12 and $18 \mathrm{cpd}$ when compared to the habitual condition. Many indoor occupations, such as surgeons, computer-involved tasks, household crafts, require adequate contrast sensitivity at high spatial frequencies and it is recommended that the white or blue A filter be used. Furthermore, it is noted that the white (clear) lens and blue A ( $85 \%$ transmission) were favourable among all spatial frequencies and perhaps could be recommended for any task.

A change in the illumination level, however, tends to create variation in contrast sensitivity ${ }^{7}$. One of the purposes of tinted lenses is to decrease illumination and thereby decrease sensitivity to light ${ }^{22}$. Darker tints tend to decrease illumination more than lighter tints. Furthermore, darker tints cause pupil dilation allowing for a greater degree of aberrations ${ }^{23}$. Since high spatial frequencies are associated with more detailed tasks, these are perhaps the reasons why darker tints have reduced contrast sensitivity function at high spatial frequencies. Alternatively, darker tints improve contrast at low spatial frequencies possibly due to the tints decreasing glare, thus having the highest contrast sensitivity function at low spatial frequencies.

With lighter tints however, the illumination reaching the retina is neither decreased as much and nor does the pupil size change as much as with darker tints, which is probably why lighter tints allow for better contrast sensitivity function at high spatial frequencies. An inverse relationship is confirmed, where, if there is an increase in the density of the tint, there is a decrease in illumination and also glare. However, rather importantly, it should be noted that the varying tints and their densities affect different spatial frequencies differently. Ramkissoon and Ferreira $^{22}$ found similar results in 2002. Hence, when prescribing tints the spatial arrangement of the tasks must be considered.

\section{Colour Vision}

Using the American Optical Hardy Rand Rittler test, the different colour tints and their varying grades did not cause a colour deficiency in any of the participants. Although there was some deviation from the habitual, it was minimal. According to Cohen $^{24}$, this can be explained by the theory of colour constancy, where our perception of colour remains constant when viewing an illumination independent object. The white lens was found to cause some form of enhancement or reduction in some of the participants, this is perhaps explained by Griffiths ${ }^{25}$ who stated that, an enhancement or reduction in colour perception may be due to distortion of light by the lens.

Grey lenses were found to have a positive effect on more of the sample when compared to brown and blue. This could be related to the fact that such tints do not distort colour much since their transmission is roughly constant throughout the visible spectrum ${ }^{1}$. The greatest reduction in colour perception was experienced with blue tints as they distort visible light by allowing greater transmission of shorter wavelengths of the spectrum. Furthermore, blue tints were also found to cause greater pupil dilation ${ }^{23}$, which may result in chromatic aberrations. Therefore blue tints are contra-indicated for outdoor use.

The findings for the grade A tints were similar to those of Ramkissoon and Ferreira ${ }^{22}$ who explained that lighter tints result in the less deviation from the habitual condition. The trends found by the blue and brown lenses were different from those of de Fez et $a l^{7}$ and Ramkissoon and Ferreira ${ }^{22}$ in that they found greatest distortion with higher densities and less with 
lower density tints. This may be attributed to the fact that the previous studies ${ }^{7,22}$ used the Farnsworth Munsell 100 Hue to test colour perception. For further studies though, it is recommended that a more quantitative test for colour vision be used, as colour vision results in this study could not be directly quantified. The results found in this study may be contrary to what may be expected, in that darker tints may be avoided due to assumption that it may hinder colour perception. Therefore, the grade of the tint must be looked at in conjunction with the colour of the tint when prescribing.

\section{Conclusion}

When prescribing tinted spectacle lenses regardless of the reason, one must consider the effect they may have on the person's visual performance. The results of this research indicated that the white (clear), grey, brown and blue spectacle lenses and their varying grades do not cause any marked alteration in colour vision though they may influence contrast sensitivity, which may affect image quality. The findings showed that the different tints and their grades affect different spatial frequencies differently therefore, the spatial detail of the tasks must be acknowledged. Furthermore, different tasks may necessitate prescribing different tints and/or grades in the same patients. On the other hand, it is also important to advise patients choosing tinted lenses (for cosmetic purposes) of their effects. Information herein should assist the optometrist when managing patients, with different requirements for tinted spectacle lenses, as it is essential that optical devices do not have any adverse effects on a person's visual performance.

\section{Acknowledgements}

We thank Mr I Niemand from Focus Network Laboratory in corporation with Genop for kindly supplying us with the study lenses. We would also like to thank Ms F Nkwanyana for assistance with the statistical analysis.

\section{References}

1. Jalie MO. Ophthalmic Lenses and Dispensing. $2^{\text {nd }}$ ed. England: Elsevier Health Sciences, 2003.

2. Ramkissoon P, Mehta M, Bhagwanjee AM. A comparison of the effect of reduced illumination and tinted lenses on stereopsis at near. The South African Optometrist. 200766 (1) 3-11.

3. Thibos LN, Hong X. Clinical applications of the ShackHartmann aberrometer. Optometry and Vision Science 199976 817-825.

4. Khurana AK. Theory and Practice of Optics and Refraction. $2^{\text {nd }}$ ed. New Delhi, India: Reed Elsevier India Private Ltd, 2008.

5. Wilkinson P. Spectacle Lens Tints with Practical Applications. http://findarticles.com/p/articles/mi_6855/is_14_47/ ai_n28447580/2007, Date accessed: 11/03/11.

6. Grosvenor T. Primary Care Optometry. $2^{\text {nd }}$ ed. Honk Kong: Butterworth Heinemann, 2007.

7. de Fez MD, Luque MJ, Viqueira V. Enhancement of contrast sensitivity and losses of chromatic discrimination with tinted lenses. Optometry and Vision Science 200279 (9) 590-597.

8. Zoltan B. Vision Perception and Cognition: A Manual for the Evaluation and Treatment of the Adult with Acquired Brain Injury. $4^{\text {th }}$ ed. USA: Slack Incorporated, 2007.

9. Diez-Ajenjo MA, Capille P. Spatio-temporal contrast sensitivity in the cardinal direction of colour space. A review. Journal of Optometry 20103 (2) 16-19.

10. Eskridge JB, Amos F, Bartlett JD. Clinical Procedures in Optometry. New York: Lippincott, 1991 pp 99-120.

11. Dain SJ, Wood JM, and Atchison DA. Sunglasses, traffic signals, and colour vision deficiencies. Optometry and Vision Science 200886 (4) 296-305.

12. Williams GJ, Kitchener G, Press LJ, Schieman MM, Steele GT. The Use of Tinted Lenses and Colored Overlays for the Treatment of Dyslexia and Other Related Reading and Learning Disorders. http://www.aoa.org/x5418.xml. 2004 Date accessed: 03/03/11.

13. Diego CA, Montes-Mico R, Pons AM, Artigas JM. Influence of the luminance level on visual performance with a disposable soft cosmetic tinted contact lens. Ophthalmological and Physiological Optics 200121 (5) 411-9.

14. Montes-Mico R, Alio' JL. Distance and near contrast sensitivity function after multifocal intraocular lens implantation. Journal of Cataract and Refractive Surgery 200329 703-711.

15. Pesudovs K, Hazel CA, Doran RML, Elliott DB. The usefulness of Vistech and FACT contrast sensitivity charts for cataract and refractive surgery outcomes research. British Journal of Ophthalmology 200388 (1) 11-16.

16. Belluci R Scialdone A, Buratto L, Morselli S, Chierego A, Moretti G, Piers P. Visual acuity and contrast sensitivity comparison between Tecnis and AcrySof SA60AT intraocular lenses: A multicenter randomized study. Journal of Cataract and Refractive Surgery 200531 (4) 712-717.

17. Richman EE. Requirements for Lighting Levels. http:// www.wbdg.org/pdfs/usace_lightinglevels.pdf. Date accessed: $12 / 03 / 13$.

18. National Research Council U.S Committee on Vision. Procedures for Testing Colour Vision, Report of Working Group 41. Washington, USA: National Academy press, 1981. 
19. Laerd Statictics. Wilcoxon Signed-Rank Test using SPSS. https://statistics.laerd.com/spss-tutorials/wilcoxonsigned-rank-test-using-spss-statistics.php. Date accessed: $12 / 03 / 13$

20. Lee J, Stein J, Prevor M, Seiple W, Holopigian K, Greenstein V, Stenson S. Effect of variable tinted spectacle lenses on visual performance in control subjects. Contact Lens Association of Ophthalmologists 200228 (2) 80-82.

21. Banks Ms. Visual recalibration and the development of contrast and optical flow perception. In: Yonas, A, ed. Perceptual Development in Infancy. $1^{\text {st }}$ ed. Hillsdale: Lawrence Erlbaum Associates, 1988 pp 145-161.

22. Ramkissoon P, Ferreira JT. The effect of tinted lenses on colour discrimination and contrast sensitivity. The South African Optometrist 200261 (3) 91-96.

23. Marmor MF. Double Fault! Ocular hazards of a tennis sunglass. Archives of Ophthalmology 2001119 (7) 10641066.

24. Cohen J. Colour constancy as counterfactual. Australasian Journal of Philosophy 200886 (1) 61-92.

25. Griffiths G. Prescribing tints: measuring colour preference in the practice. Optometry Today 200343 (19) 51-53. 